\title{
LOS VALORES MORALES EN LA CONDUCTA PERSONAL
}

\author{
Boris Aguirre Palma ${ }^{1}$
}

\begin{abstract}
RESUMEN
¿Cómo hacer énfasis y empoderar en conductas humanas propositivas mediante el aprecio y adquisición de valores morales? La afirmación y práctica de valores son indispensables en toda agrupación humana para la convivencia pacífica en el ecosistema familiar, las instituciones y la misma sociedad. Nacemos como todo animal con algunos instintos que son comportamientos que no tienen que ser aprendidos, por ejemplo, llorar cuando tenemos hambre o sed y succionar la leche de nuestra madre. Pero como seres racionales tenemos también que aprender muchas conductas indispensables para sobrevivir en este mundo, no llegamos a él como un producto terminado. El comportamiento de cada persona puede ser saludable o no. Lo indispensable para que lo sea, es que siempre sea correcto y que, para este propósito, se fundamente en valores morales cultivados y adquiridos preferentemente desde edad muy temprana en su medio familiar y social. En la formación de los hábitos de toda persona influye en diverso grado una serie de factores guías, "mapas mentales", condicionamientos económicos y del medio ambiente, preceptos o patrones culturales, normas sociales, procesos psico- afectivos propios de cada individuo, convicciones religiosas y valores morales. Algunos de estos factores actúan preferentemente en los primeros años de vida; otros, como los valores que suponen más reflexión, requieren mayor madurez. En este trabajo nos referiremos a los valores especialmente en algunas conductas: respeto y protección activa del entorno físico en que vivimos, lealtad, justicia, equidad de género, solidaridad, empatía, tolerancia, serenidad, conciliación, libertad de conciencia, respetuoso manejo de la sexualidad, entre otras. Muchas de las reflexiones y recomendaciones que presentaremos, tendrán como marco de referencia la gestión familiar. En el presente estudio analizaremos cómo los valores juegan un papel protagónico en el proceso de toma de decisiones como en la formación de conductas y de hábitos de vida. El tema del ecosistema familiar se convierte en el punto central cuando vamos a hablar de comportamientos y hábitos. La familia es la organización básica de toda sociedad; ella forja a las mujeres y los hombres que han de manejarla; tiene un papel determinante en la construcción de actitudes humanas saludables que nacen en su seno - y hasta en ocasiones son adulteradas en su
\end{abstract}

\footnotetext{
${ }^{1}$ Universidad Tecnológica Equinoccial, Facultad de Ciencias de la Ingeniería, Av. Occidental y Mariana de Jesús. Quito, Ecuador. baguirre@ute.edu.ec
} 
interior- muy importantes todas en el diario vivir; $y$, finalmente, contribuye muy eficazmente a la formación de conductas y de hábitos muy importantes para la persona y para la inter - acción con su comunidad.

\section{INTRODUCCIÓN}

¿Cómo fundamentar y robustecer saludables conductas humanas mediante el aprecio y adquisición de valores morales? Este es el objetivo de las siguientes recomendaciones basadas en reflexiones de carácter ético, psicológico, antropológico y didáctico en el contexto del convivir familiar, social y del entorno físico que nos rodea.

La afirmación y práctica de valores son indispensables en toda agrupación humana para la convivencia pacífica en el ecosistema familiar, las instituciones y de la misma sociedad. La ausencia de estos valores, obviamente se evidenciará en comportamientos estimulados o por impulsos instintivos, o por la atracción poderosa de inmediatas gratificaciones sensitivas o por motivaciones carentes de preocupación por el necesario respeto a las personas y a todo el conjunto social en el que actuamos y vivimos.

Puesto que el ser humano está constantemente expuesto a una variedad de estímulos que le exigen respuestas o comportamientos, es importante tener en cuenta que ninguna persona reacciona automáticamente como un ordenador que no tiene más alternativa que obedecer a un determinado comando electrónico, bajo el impulso del instinto. Antes de cada respuesta suya entran en juego, a velocidades vertiginosas, motivaciones que 1 presentan una serie de conductas alternas para cada estímulo, las que tiene que analizar para decidirse por una de ellas.

Este intermedio entre una acción y reacción es el que tenemos que saber emplear inteligentemente a fin que nuestras respuestas estén precedidas de una motivación positiva y constituyan una conducta saludable, es decir respetuosa y beneficiosa personal y socialmente. Un saludable comportamiento es el resultado de convicciones profundas, una manifestación del dinamismo de los valores efectivamente operantes que una persona haya adquirido.

Como parte de esta introducción es conveniente recordar brevemente la vinculación entre estímulos, comportamientos o conductas y los hábitos que de éstas pueden generarse.

\section{ESTÍMULOS, CONDUCTAS Y HÁBITOS}

Nacemos como todo animal con algunos instintos que son comportamientos que no tienen que ser aprendidos, por ejemplo llorar cuando tenemos hambre o sed y succionar la leche de nuestra madre. Pero como seres racionales tenemos también que aprender muchas conductas indispensables para 
sobrevivir en este mundo, pues no llegamos a él como un producto terminado, sino con grandes necesidades de adaptación y a la vez con una inmensa capacidad para lograrla y para crecer en muchas direcciones, mediante la adquisición de nuevas conductas, la modificación de las adquiridas ya y hasta el control de las instintivas.

Cada comportamiento tiene consecuencias agradables o desagradables que actúan o como refuerzos estimulantes para repetirlo o como inhibidores para evitarlo. En los animales, las consecuencias agradables inmediatas muy fácilmente se transforman en hábitos que escapan completamente a su control y que un entrenador puede aprovechar. Afortunadamente, en los seres humanos si bien hay algunas conductas instintivas, la inmensa mayoría de sus comportamientos son respuestas no automáticas ni absolutamente incontrolables, a los estímulos que les rodean.

No todo comportamiento humano se hace costumbre pero sabemos que su reiteración puede ser causa de la formación de hábitos que, por una parte, hacen que los seres humanos frecuentemente actúen de una forma casi automatizada y, por otra, determinan muchas de sus formas de relacionarse con los demás y con su entorno. Cada comportamiento de una persona puede ser saludable o no. Lo indispensable para que lo sea es que siempre sea correcto y que, para este propósito, se fundamente en valores morales cultivados y adquiridos preferentemente desde edad muy temprana en su medio familiar y social.

Pero no se aprende a comportarse únicamente como resultado de haber recibido una educación familiar excelente. Existen condicionantes que tienen una incidencia muy fuerte en los comportamientos de una persona que se los podría agrupar de la siguiente forma:

- Predispositivos: estimulantes o inhibidores previos que pueden facilitar o entorpecer el proceso de motivación y por consiguiente promover o inhibir determinadas conductas, por ejemplo actitudes, opiniones, creencias, sentimientos, convicciones surgidas de procesos racionales y críticos o también de tabúes, percepciones, intereses, nivel de conciencia con respecto a la existencia de un problema, códigos éticos personales y morales. Muchos de estos factores son parte del ecosistema familiar - arquetipo de los padres (proceso de socialización), otros son incorporados por el mismo individuo como su patrimonio personal y cultural.

- De Refuerzo: recompensas o experiencias negativas y dolorosas posteriores a un comportamiento que motivan o inhiben su repetición porque pueden ser anticipadas y esperadas, como gratificaciones de tipo físico, satisfacciones emocionales, aprobación, 
alabanzas, premios, desaprobación, rechazos, castigos, etc. El control y/o soporte social que la persona recibe luego de haberse comportado de cierta forma, trae consigo una serie de consecuencias importantes en la modificación de sus conductas. Estas consecuencias, especialmente de aprobación o desaprobación, son generalmente mediadas por la familia, pero también por la comunidad en general, por líderes, empleadores, trabajadores de la salud, oficiales de gobierno, amigos, compañeros de grupo y otros públicos importantes para la persona.

La repetición y sistematización que haga la persona de estas experiencias se convertirán en factores que le predisponen a posibilidades de reincidir en el futuro en las mismas conductas. Esto resulta cuando los deseos de repetir cierto comportamiento, debido a la percepción que la persona tiene los beneficios que podrá obtener, son claramente mayores que el temor de los costos o barreras que potencialmente le pueden estorbar.

Se considera que esta clase de factores que refuerzan el comportamiento juegan un papel crítico en el aprendizaje social. Vrg. Cuando más refuerza el grupo un comportamiento, más crece la posibilidad que la persona lo repita. Muchos comportamientos indeseables que observamos en la sociedad son el resultado -que en cierto modo se da en muy corto plazo- de ciertas satisfacciones placenteras (ventanas de placer inmediatista), mientras que al mismo tiempo se silencian las consecuencias negativas que vendrán a mediano y largo plazo.

- Mediadores: factores externos que actúan como mediadores y pueden facilitar o dificultar determinados comportamientos, por ejemplo estructuras y sistemas sociales, recursos disponibles o no accesibles a la persona, medios de transporte, equipos, infraestructura, instalaciones sanitarias, etc.

Como se indicó arriba, no todos los comportamientos humanos se vuelven hábitos. En la formación de los hábitos de toda persona influye en diverso grado una serie de factores guías, "mapas mentales", condicionamientos económicos y del medio ambiente, preceptos o patrones culturales, normas sociales, procesos psico- afectivos propios de cada individuo, convicciones religiosas y valores morales. Algunos de estos factores actúan preferentemente en los primeros años de vida; otros, como los valores que suponen más reflexión, requieren mayor madurez. De allí la importancia de la educación con la cual los padres pueden y deben propiciar oportunamente la formación de hábitos saludables y desalentar la de los contrarios.

En el presente estudio analizaremos cómo los valores juegan un papel protagónico en el proceso de toma de decisiones como en la formación de conductas y de hábitos de vida. El tema del ecosistema familiar se convierte en el punto central cuando vamos a hablar de comportamientos y hábitos. 
La familia es la organización básica de toda sociedad; ella forja a las mujeres y los hombres que han de manejarla; tiene un papel determinante en la construcción de actitudes humanas saludables que nacen en su seno - y hasta en ocasiones son adulteradas en su interior- muy importantes todas en el diario vivir; y, finalmente, contribuye muy eficazmente a la formación de conductas y de hábitos muy importantes para la persona y para la inter - acción con su comunidad.

En este trabajo nos referiremos a los valores especialmente en algunas conductas: respeto y protección activa del entorno físico en que vivimos, lealtad, justicia, equidad de género, solidaridad, empatía, tolerancia, serenidad, conciliación, libertad de conciencia, respetuoso manejo de la sexualidad, entre otras. De acuerdo con nuestra visión, muchas de las reflexiones y recomendaciones que presentaremos, tendrán como marco de referencia la gestión familiar.

\section{LA IMPORTANCIA DE LA CONCIENCIACIÓN DE UN COMPORTAMIENTO COHERENTE CON EL CONTEXTO FÍSICO}

El tipo de comportamientos y hábitos que desarrollen los seres humanos determinan en gran parte el tipo y calidad de vida que tendrá esa persona, su ecosistema familiar y grupo social al que pertenezca. De la misma manera, los comportamientos son el medio para crear o modificar el contexto,

En estos primeros siete años del siglo XXI, podemos apreciar como toda la superficie terrestre del planeta ya ha sido gravemente alterada por la intervención del ser humano. Especialmente, en la última centuria, el ser humano ha dejado su huella en todas partes, alterando compulsivamente el medio ambiente natural existente por millones de años.

La vegetación, los animales, el agua y aún el aire han sido violentamente agredidos de muchas formas. Hasta las aguas del subsuelo han sido contaminadas, o seriamente empobrecidas. La ecología antropogénica es fruto de estos comportamientos. El ser humano, a través de ellos, ha ido construyendo su propio hábitat que poco tiene que ver ahora con el Medio Ambiente Natural en el cual anteriormente vivía en permanente y directa interdependencia.

Si bien los cambios muchas veces han buscado mejorar calidad de vida y disminuir el desgaste laboral, frecuentemente el tipo de viviendas, edificios, industrias, medios de transporte, asentamientos humanos, etc., han sido establecidos de una forma irreflexiva e irresponsable. Esto ha determinado la multiplicación de un gran grupo de factores de riesgo que no sólo le impiden al ser humano disfrutar de la vida a plenitud, sino que están amenazando su misma existencia. El Medio 
Ambiente Antropogénico es un caldo de cultivo que desarrolla una cultura de muerte que atenta contra la vida, no sólo de la especie humana, sino de todos los seres vivos. La organización social y el tipo de tecnología, que rápidamente llega a todo, amenazan la subsistencia de las diferentes formas de vida que se conocen.

Efectivamente, somos testigos de la presencia cada vez mayor de comportamientos que promueven o defienden la vida, pero también, y muy tristemente, de comportamientos que originan condiciones de muerte, a los que se les denomina comportamientos de riesgo, entre los que mencionamos:

- Riesgos por comportamientos personales que atentan contra la salud: Vrg. fumar cigarrillo, consumir en exceso bebidas alcohólicas, no asearse adecuadamente, vrg. No lavarse los dientes.

- Riesgos por comportamientos familiares que atentan contra la salud: Vrg. la familia desunida, donde cada uno hace lo que quiere.

- Riesgos por comportamientos comunitarios que atentan contra la salud: Vrg. una comunidad no organizada para cuidar sus fuentes de agua.

- Riesgos por comportamiento del Estado que atentan contra la salud: Vrg. políticas sociales y económicas que atentan contra los sectores populares.

El estado de "salud" de los pueblos resulta determinado principalmente por el comportamiento personal, familiar y colectivo de su ecumene. Por eso, el papel de la educación es muy importante en la construcción de una sociedad más saludable, siempre y cuando este proceso educativo busque facilitar desarrollar seres responsables con su vida y con su entorno y no simplemente ser una simple transmisión de información.

Se puede advertir cómo este elemento de responsabilidad en la vida es resultado del desarrollo de una serie de valores que hacen que la persona no se comporte sobre la base de respuestas mecánicas a los estímulos que recibe, sino como resultado de juicios razonados que permiten reparar consecuencias a corto, mediano y largo plazo no solo para la persona misma, sino para la sociedad y el entorno que le rodea. Una persona que estructura sus comportamientos sobre la base de una serie de valores comprometidos con la vida estará siempre contribuyendo con la construcción de un mundo más humano y justo para todos en esta y las siguientes generaciones. 


\section{HACIA LA FORMACIÓN DE VALORES PARA EL ENRIQUECIMIENTO DE LA CALIDAD DE VIDA}

La carencia de valores ha permitido, a la sociedad en general, reconocer rápidamente los daños desastrosos que muchos de estos comportamientos traen a mediano y largo plazo, ha abierto una carrera desenfrenada por la búsqueda momentánea de placer. La sociedad consumista se ha encargado en hacer ver estas consecuencias como remotas, inciertas o irrelevantes, con tal que los seres humanos consuman el producto que se les ofrece.

Resulta vital que, quienes consideran la importancia de formar seres humanos responsables, busquen formas de crear espacios de reflexión donde se pueda visualizar cómo la carencia de valores nos puede conducir hacia una sociedad inhumana y mucho más salvaje que cualquier otra especie en el planeta, ello por el gran potencial que tenemos de usar la inteligencia en procesos autodestructivos.

Los valores, generados por una serie de creencias y opciones de fe que desarrollan códigos éticos y morales en los seres humanos, permiten modificar y reestructurar marcos teóricos y conceptuales sobre nosotros mismos, los demás y el entorno, permitiendo desarrollar una serie de conductas eminentemente positivas, fruto de opciones y motivaciones internas que guían los comportamientos de la persona a pesar de no haber motivadores externos.

Cuando los seres humanos deciden comportarse de ciertas formas, como consecuencia de factores mediadores y que refuerzan, externos a la persona, estas conductas pueden ser modificadas fácilmente cuando el agente externo no esté presente o cuando aparezca un nuevo agente externo que le ofrezca cierta ganancia o beneficio que no era obtenible por la conducta previa. En seres humanos que guían sus comportamientos a través de motivadores internos y valores, su pensar y actuar es mucho más independiente de la presencia o ausencia de elementos externos.

En la tarea de buscar la modificación de comportamientos de los diferentes factores que predisponen, median y refuerzan, a través de procesos de aprendizaje orientados a la toma de acciones, es crucial que la temática del desarrollo de valores ocupe un papel protagónico. Los valores permiten a los seres humanos trascender el momento y coyuntura en que se encuentran, proyectándose en el tiempo y en el espacio para sopesar sus deseos instintivos y considerar las repercusiones que tienen las diferentes conductas alternativas ante una situación.

Los valores se construyen a partir de una serie de creencias y opciones -algunas de fe religiosa- que cimentan los elementos fundamentales de nuestra identidad, nuestro sentido de existencia y nuestra razón para vivir. Es más, si se quiere edificar una nueva sociedad, lo cual demanda la formación de 
seres humanos con una serie de conceptos, actitudes y capacidades para promover esos cambios, se requiere una reestructuración no sólo de los procesos mentales congnitivos sino de otras dimensiones del ser humano.

En el proceso de cambio es importante prestar especial atención a la modificación de las actitudes y creencias. Los valores, las ideas o conceptos acerca de lo que cada uno de nosotros cree o siente que tiene una importancia crucial para nuestras vidas, guían los procesos de toma de decisiones de nuestro diario vivir. El desarrollo de una comprensión clara de un valor capacita a los seres humanos para tomar decisiones que concuerden con aquello que ellos creen.

Las actitudes son consideradas como una combinación de creencias, sentimientos y evaluaciones acoplados con una predisposición para actuar en conformidad a esa combinación (Gletman, 1995). Las actitudes van entrelazadas con los valores y generan los afectos en los seres humanos. Estas actitudes explican, en gran parte, por qué la gente reacciona a políticas, a objetos específicos, etc. (Sabini, 1994). Diferentes individuos tendrán diferentes actitudes con respecto al cambio (o ciertos componentes del cambio) que les hará más deseosos a participar en el cambio o a resistirlo. Un proceso organizado para promover una transformación social requiere de un modelo conceptual que permita identificar las actitudes de los seres humanos durante el proceso de cambio para ser sensibles a sus intereses y desarrollar estrategias apropiadas de intervención.

El modelo de "estados de cambio" de Prochaska y DiClemente (1986) y Cohen, Halvorson y Gosselink (1994) son de gran utilidad para comprender mejor la relación que las actitudes y valores tienen con respecto a la disponibilidad y capacidad de los seres humanos para involucrarse en procesos de cambio con respecto a sí mismo y con respecto al entorno.

1. El estado de preconsciencia se refiere al estado en el que se encuentran seres humanos cuando no piensan ni se dan cuenta de la necesidad de realizar ciertos cambios.

2. El estado de consciencia es aquel en el que la persona piensa acerca de la situación y la posibilidad del cambio pero no realiza ningún intento o plan específico para hacerlo.

3. El estado de preparación es aquel en el que la persona está en proceso de hacer planes para una pronta renovación.

Este proceso de reforma puede facilitarse a través de elementos provenientes de afuera que presionen a la persona a considerar la posibilidad de la variación y comprometerse con esta, pero también pueden lograrse a través del desarrollo de fuerzas internas a las seres humanos, o elementos motivadores personales, que la empujen a progresar a través de los estados de la innovación. 
Cambios logrados solo por elementos externos hacen que la persona fácilmente tenga recaídas o retorno a estados previos haciendo más difícil la permanencia en el estado de mantenimiento. Cuando la persona asume completa responsabilidad por su proceso de renovación a causa de una motivación interna el mantenimiento en la modificación de conductas se vuelve estable ya que no depende tanto de circunstancias externas sino de opciones de fe y convicciones personales para el cambio. La afirmación de valores y/o el desarrollo de estos en los seres humanos son importantes motivadores internos que facilitarán cambios sostenibles.

\section{¿COMO SE FORMAN LOS VALORES?}

Ciertamente que, los mayores determinantes de valores en cada persona son las creencias y opciones de fe que decide tomar. Este proceso, se inicia en los primeros años de vida sobre la base del arquetipo y presentación de verdades y obligaciones a los/as niños/as que hacen los padres y otras personas reconocidas como autoridad. Frecuentemente, se piensa que los valores se transmiten a través de la enseñanza verbal de los padres y que serán los que determinarán los comportamientos posteriores.

En el proceso de socialización, es dable que lo que sucede sea lo contrario a lo que determinan los comportamientos en la vida adulta (creencias y valores determinan comportamientos). Aquellos comportamientos que sean modelados por los padres y otras figuras de autoridad, y que sean estimulados en los/as niños/as, consistentemente reforzados para que se repitan en diferentes situaciones, van interiorizando en el/a niño/a una serie de significados, valores, normas y expectativas relacionadas con esos comportamientos "aprobados" por la persona en autoridad.

Estos elementos son los que van formando la personalidad del/a niño/a, al mismo tiempo que van ayudando a desarrollar un concepto de lo que debería ser su proyecto de vida, así éste sea completamente inconsciente y difícil de visualizar. El entorno familiar va comunicando a los/as niños/as sus valores al mismo tiempo que los desarrolla por medio de comportamientos que dan significado y razón de ser a sus vidas.

Las familias y las instituciones que trabajan con niños deben identificar claramente qué es lo que quieren en la vida como padres de familia o institución que cuida de ellos/as, para que puedan facilitarle el desarrollo de sus propios proyectos de vida, con sueños, ilusiones y valores de una forma clara que sea su Norte en su pensar, su sentir y su actuar. Estos valores les permitirán tener una vida más equilibrada y armónica con su entorno, sabiendo cuidar aquellas cosas que son cruciales para su desarrollo como seres humanos saludables y miembros de familias y comunidades. 
El diálogo permanente es fundamental para identificar cuáles son los valores que a nivel de familia se quiere perpetuar y cómo estos se expresan a través de los diferentes comportamientos. Vrg., si se habla de la responsabilidad que todos tenemos de respetar el valor de la vida, se deben construir modelos de cómo en la vida cotidiana se aprende a ocuparnos responsablemente de nosotros mismos y de los demás, y puedan experimentar la vida a plenitud.

De la misma manera, se pueden buscar modelos de cómo se puede cuidar y proteger la vida de otros seres vivos como animales menores, algunas hortalizas que se siembren, las flores del jardín, etc. El ver el rol que cada forma de vida tiene en el enriquecimiento y plenitud de las otras formas de vida, permitirá redescubrir la santidad de la vida en todas sus formas. Resulta interesante poder unir este valor de respeto a la vida con el valor de la lealtad. La vida solo es posible si hay armonía en los elementos que se requieren para que se dé. La ausencia de algunos de estos elementos o un rol disfuncional que rompa esta armonía constituyen el principio de una amenaza para la vida.

\section{APRENDIENDO A EJERCER LAS VIRTUDES HUMANAS SOBRE LA BASE DE VALORES}

Nos referiremos aquí, como ejemplos a la lealtad, la justicia, complementariedad entre los géneros, otros como la gratitud, solidaridad y servicio. Concluiremos con unas reflexiones sobre elogios, premios, castigos, y el diálogo de amor, crítico y analítico de familia.

Puesto que somos seres esencialmente relacionados, diariamente nos encontramos con la necesidad de ejercitar o adquirir determinadas formas de comportamientos que garanticen esta vinculación, como la lealtad, la paciencia, la justicia y muchas más a las que podemos llamar virtudes humanas. El presente trabajo considerará algunas de ellas.

La lealtad razonada y no ingenua es la capacidad de comprometerse con el bien del otro, así eso signifique hacer sacrificios y renunciar a cómodas posiciones personales La lealtad es permitir que prevalezcan los valores y cosas que unen por encima de las coyunturas difíciles que dividen o separan, es proteger el valor de la honestidad que impide el defraudar al otro, que de alguna forma ha entretejido su vida con los demás.

La lealtad es comprender que el amor no es posible sin opciones de responsabilidad y fidelidad a pesar de las circunstancias. La lealtad ayuda a entender el papel del valor de la disciplina para auto controlarse y cumplir con los deberes y objetivos que se ha trazado y estar dispuesto a renunciar a satisfacciones o placeres temporarios en procura de un bien mayor. La lealtad es el elemento fundamental que da consistencia y solidez a los proyectos de vida entretejidos con otros seres humanos a través de compromisos y responsabilidades que se van desarrollando a través del tiempo. 
La lealtad es quizá el valor más grande en toda interpelación humana, generador a su vez de otros importantísimos valores como la justicia, la solidaridad, el servicio, la comunicación honesta y transparente, etc. Consecuencia de un profundo respeto mutuo, la lealtad es simultáneamente su prueba más evidente y la condición indispensable de toda relación verdadera y del cultivo de otras virtudes que a la vez necesitan y la perfeccionan.

La paciencia y la tolerancia, por ejemplo, se cultivan mejor en circunstancias en las que la lealtad es fundamental. Es más fácil aprender a sufrir y tolerar sin perturbación de ánimo, los trabajos o infortunios, las frustraciones y las tensiones que muy fácilmente se dan con el trato con los demás, cuando sabemos que por encima de todo debemos ser leales. Aprendemos a esperar con tranquilidad y calma cuando sabemos que la vida significa mucho más que las desagradables experiencias de un momento.

La justicia: Para promover el valor de ser justos, se puede construir modelos de cómo el aprender a tener en cuenta y respetar a los demás, especialmente a los más débiles, sin importar raza, credo y posición social -ser cortés y equitativo considerando a los otros y buscando respetar las necesidades y sentimientos de los demás, etc.- permite aprender a vivir en armonía, pudiendo enriquecerse unos con otros y así poder disfrutar la vida a plenitud.

Hay que tener cuidado al promover el valor de la justicia, de no identificarla con "igualdad". El vivir en justicia frecuentemente supone aun aprender a preocuparse por los derechos y sentimientos de los demás dentro de su propio contexto que no es necesariamente igual sino muy probablemente diferente.

Además, la justicia exige consideraciones especiales para quienes han infringido los derechos de otros. Es obvio que los niños no aprenderán a respetar a estos infractores, si los padres y las personas en autoridad no los respetan. Desafortunadamente, tampoco aprenderán siquiera a respetarse a sí mismos y a buscar y exigir que los demás les respeten. Es más importante comprender que la justicia más que reclamar derechos individualmente, exige un esfuerzo por aprender a cooperar con los otros para satisfacer las necesidades de ambas partes de una forma equitativa, es decir de las necesidades de cada uno en su propia realidad, etc. La justicia muchas veces supone el superar la tendencia al egoísmo e ir más allá de los acuerdos y reglas o "caminar la segunda cuadra" para buscar qué es lo mejor para todos.

De la misma manera, se puede examinar modelos de cómo al ignorar este valor de la justicia, enraizado en el respeto mutuo, se generan abusos que crean resentimientos y odios que serán 
generadores de muchas formas de violencia y conflictos sociales. Significa más que reclamar derechos individualmente, es aprender a cooperar para satisfacer las necesidades de ambas partes de una forma equitativa (que depende mucho de las necesidades de cada uno, el contexto, etc.) que permitan promover relaciones más humanas y equitativas entre los involucrados. La justicia es muchas veces superar la tendencia al egoísmo e ir más allá de los acuerdos y reglas o "caminar la segunda cuadra" para buscar qué es lo mejor para todos. De la misma manera, se pueden ver modelos de cómo al pisotear este valor de la justicia se generan condiciones de injusticia y abuso que crea resentimientos y odios que serán generadores de muchas formas de violencia y conflictos sociales.

La complementariedad entre los géneros: Es una lógica consecuencia de la esencial vinculación del hombre y la mujer en un plano, por una parte de igualdad en dignidad y derechos y por otra de necesaria inter - dependencia, no sólo como pareja para su apoyo mutuo sino como padres de nuevos seres en una familia cuya generación, crecimiento y formación depende de ellos.

Dentro de este marco referencial de complementariedad conyugal y familiar, el menosprecio, abuso y aun maltrato por diferencias de género es un problema que, aunque lastimosamente está presente en la mayoría de los espacios de la cultura, pone en grave riesgo de irreparable destrucción tanto a la sociedad conyugal como a la familiar.

El respeto práctico por la equidad de género, sin lugar a dudas debe iniciarse en el arquetipo dado por la relación entre el padre y la madre. La observancia de este comportamiento en los padres, como la insistencia y estímulo de relaciones de equidad en todos los comportamientos de los hijos (entre ellos como con otros niños/as), progresivamente irán desarrollando una forma de "ser" y "querer ser" que constituirán un excelente cultivo de los valores propios de una positiva complementariedad de géneros y simultáneamente de una familia preocupada por la formación personal de sus hijos que se manifestará en conductas saludables familiar y socialmente.

Estos comportamientos se expresan en actividades cotidianas como no separar los juguetes de niñas y niños ni "asignar" cierto tipo de juguetes para el niño y la niña. Las muñecas, los carritos, los juegos de armar y las pelotas son necesidades de todos para un buen desarrollo psico-afectivo y motriz. De la misma manera, el cuidado de los hermanos menores debe ser una actividad compartida entre los mayores independientemente del género, como también el cuidado mutuo entre hermano/as sin comunicar que son los niños los que deben cuidar a las niñas. Debe buscarse cuestionar personajes sociales, políticos héroes de la televisión, cuando estos muestran poca representatividad de personajes de uno de los dos géneros. No deben utilizarse frases que promuevan estereotipos como "a las mujeres no se les pega", "no llores, que pareces una niña" o "los hombrecitos no sienten miedo". 
El uso de violencia física es reprobable, independientemente del género que tenga la persona. Las expresiones de sentimientos son válidas sin importar el género. En los permisos a los/as hijos/as, hay que tener mucho cuidado de mostrar permisividad a los niños y restricciones a las niñas ya que esto perpetúa una sociedad donde el hombre puede disfrutar de más libertades, mientras a la mujer es normal limitarle sus libertades.

La gratitud: a fin de cultivar el valor de "ser agradecido" conviene buscar modelos en los que los niños reconozcan y dignifiquen la labor de los demás expresando su agradecimiento a quienes se esfuerzan por respetar sus derechos, mediante el cumplimiento de sus obligaciones y deberes según las responsabilidades que les fueren confiadas o de acuerdo a ciertos objetivos previamente definidos.

La solidaridad: Para promover los valores de la solidaridad y el servicio se pueden construir modelos en los que los miembros del ecosistema familiar teniendo en cuenta las necesidades de todos los componentes del grupo, realicen tareas para el servicio y beneficio de todos, sin esperar ni pedir nada a cambio.

El humor: El humor contribuye a situar las realidades que nos afectan en una dimensión menos subjetiva. Reirnos de nosotros mismos nos permite observarnos en un contexto más real y comprender que las cosas no son ni tan graves ni tan serias ni tan fatales como aparecen. El celebrar y aun el buscar el humor son oportunidades para desarrollar un valor tan humano y tranquilizador, el genuino humor, que sin dudad alguna puede ayudarnos a todos a estar en buena disposición para ponerle un sabor alegre a la vida y gozar con sus pequeños detalles.

En la formación de valores es muy conveniente y recomendable tener en cuenta las recomendaciones siguientes:

- emplear ejemplos concretos a fin de que los miembros de la familia no sólo destaquen sino realcen su importancia.

- Elogiar más el comportamiento que a las personas para ayudar a los niños a comprender claramente la importancia de su conducta.

- Evitar recompensas materiales al premiar un comportamiento sobresaliente que manifiesta claramente la existencia dinámica en la persona de ciertos valores preestablecidos pues fácilmente obscurecen el significado de una buena conducta para el niño y su entorno familiar. 
- Premiar con actividades del gusto del niño y con palabras expresivas de felicitación.

- Cuidar muy atentamente el uso de castigos cuando los niños no responden como se espera, pues los castigos poco efecto tienen en la modificación de actitudes y motivación interna para lograr las conductas deseadas. El llamarles la atención, avergonzarlos o humillarlos trae muchos efectos negativos y no ayudan en nada a corregir conductas erradas.

- Eliminar con sumo cuidado toda forma de transmisión de prejuicios sobre las personas, costumbres, tradiciones, etc. Que nos acompañan desde la niñez.

Se debe mantener una constante preocupación crítica y analítica de nuestros valores. En un diálogo cordial de preguntas y respuestas y con una actitud positiva y de amor y afirmación se puede incentivar a los niños hacia su adquisición cuidando de no convertir estas conversaciones en "clases de instrucción", sino en espacios fraternos donde se disfruta con lo que se aprende, porque nos fortalecen como individuos y como grupo humano, porque nos ayudan a gozar plenamente la vida con sencillez, paciencia y solidaridad.

Como se mencionó previamente, el arquetipo y el estímulo para la práctica de cierto tipo de comportamientos al igual que el confrontarlos críticamente y desalentarlos, irán cultivando una serie de valores en el ecosistema familiar. Si bien es claro que la práctica cotidiana desarrolla en los niños/as determinados marcos teóricos, es también importante abordar esos marcos teóricos, preparar una lista de sus valores y comprender cómo se manifiestan en nuestro actuar cotidiano frente a las responsabilidades que tenemos que cumplir. El crear espacios y oportunidades para hablar de los valores, su pertinencia, la necesidad de reafirmarlos o modificarlos, la importancia de que todos nos comprometamos a cumplirlos, las dificultades que tenemos y las disonancias y contradicciones entre lo que afirmamos que deberíamos ser y lo que vivimos, serán ricas oportunidades para afirmar el desarrollo y vivencias de esos valores sin necesidad de recurrir a un espíritu de crítica destructiva.

\section{LOS VALORES DE CONVICCIÓN, INDEPENDENCIA Y TOLERANCIA}

Ante el influjo de la familia en la formación de valores, se presenta una serie de preguntas a las que no podemos dejar de responder. Si cada familia y grupo humano tienen sus valores ¿no se darán desacuerdos muy serios por sus inevitables diferencias? La posibilidad de conflicto es evidente. La diferencia de valores políticos, económicos, religiosos ha sido causa de sangrientos enfrentamientos, en guerras crueles e interminables a lo largo de toda la historia de la humanidad, .... Y lo es ahora también. ¿Será posible tener paz con tan profundas divergencias de creencias, opiniones y ambiciones? ¿cómo garantizar el derecho personal, familiar y comunitario a sus valores y 
simultáneamente la posibilidad de una convivencia pacífica? En esta breve sección de este estudio se sugiere el cultivo de tres actitudes intrínsecamente vinculadas entre sí, que pueden propiciar un ambiente de respeto, comprensión y paz: firmeza en las convicciones personales, independencia y libertad en la conducta consecuentemente con estas convicciones y tolerancia respetuosa de otras opiniones.

Hay una actitud que puede facilitar la coexistencia de las tres mencionadas arriba, la empatía o la capacidad de entender y asumir el papel de otra persona para comprender y reconocer sus convicciones y emociones. Su cultivo supone la persistencia en el diálogo, la retroalimentación mutua y los espacios para que todos puedan expresar lo que piensan y lo que sienten. Si no se procura este diálogo atento y respetuoso del pensamiento de cada participante, no crecerá la empatía sino que se irá desmoronando poco a poco hasta extinguirse.

Se recomienda en consecuencia que los jefes y autoridades en los ecosistemas familiar, grupal, social, institucional, etc. Reconozcan claramente la gran responsabilidad que tienen de modelar estos valores de empatía ya que no se podrá promover ni mucho menos exigir su vivencia cuando consistentemente se los ignora, descuida y hasta pisotea sin escrúpulos.

El respeto a la opinión de todos y cada uno de los miembros de la familia, por ejemplo, aunque se trate de niños todavía inexpertos, el escucharles atentamente, el reconocer todo lo positivo de su reflexión y hasta el dejarles debatir, son excelentes primeros pasos en el cultivo de la empatía que más tarde necesitarán al confrontar otras ideas y posiciones muy opuestas a las suyas. Se puede hacer planificaciones a nivel personal y de grupo para elaborar objetivos de cómo vamos a desarrollar la empatía, cómo vamos a verificar si la estamos viviendo y qué vamos a hacer cuando enfrentemos dificultades y contradicciones.

Es muy educativo observar atentamente cómo muchas familias y grupos sociales desarrollan valores diferentes y reflexionar sobre cómo debemos aprender a respetarlos y vivir en diversidad a pesar de inevitables divergencias. Debe hablarse de cómo estas diferencias y desacuerdos muchas veces ejercen fuertes presiones para que dejemos de lado nuestros propios valores sin preocuparnos del daño que este grave descuido causará a nuestro proyecto de vida.

La firmeza en las convicciones: Si es inevitable la existencia de opiniones diversas, opuestas y aun contradictorias, la necesidad de convivir con ellas no debe en ninguna forma debilitar la determinación de cada persona, familia y grupo social de robustecer las suyas. Una convicción desprovista de una base racional profundamente analizada y comprendida no es firme y muy 
fácilmente acabará por debilitarse y ceder a otros influjos y pensamientos. Es, por tanto, de necesidad absoluta, que los padres en la familia y los líderes en sus comunidades busquen la ayuda de educadores dinámicos, sólidos y convincentes, seguros de sus valores y de las razones que los fundamentan, de modo que puedan atender a su cultivo en los niños y miembros del grupo comunitario al que pertenecen.

El valor de ser independientes es una consecuencia lógica de nuestro derecho a tener nuestras convicciones propias y adherimos libremente a ellas aceptando sus exigencias, es decir a comportarnos en modo consecuente con lo que creemos. Robustecer este valor nos posibilita ejercer el derecho que tenemos a ser diferentes, de no permitir que nos presionen a vivir bajo otros criterios y convicciones distintos de los nuestros. Hay que aprender a defender nuestras convicciones, es decir hay que cultivar el valor de tener "valor" y de ser "constantes" ante cualquier situación adversa, obstáculo o provocación sin desfallecer o dejamos apartar de nuestros objetivos y principios.

El valor de ser independiente permite a la persona desarrollar entereza y firmeza de carácter para decidir por sí misma qué es bueno y qué es malo, qué se hace y qué no, teniendo presente que la mayor responsabilidad del ser humano es definir libremente su propia vida, sin permitir que sean otros quienes la determinen y actuar en ella por sí mismo de acuerdo a sus convicciones. No es fácil ser firmes en la vida, ni son claros los caminos por los que hay que optar. Una vez más cada individuo, especialmente el niño, necesita educadores que le enseñen a tener valor para elegir y para correr los riesgos razonables e inevitables que son parte de toda decisión humana, requiere, por tanto, de maestros y guías para estar dispuesto a ser diferente.

El valor de la tolerancia: el ser independiente y el mantener las convicciones con firmeza no significa ni atrincherarse rígidamente en determinadas convicciones, ni pretender ser dueños de la verdad, ni rechazar y desdeñar ideologías y puntos de vista. El afán y el esfuerzo por vivir en consonancia con nuestras convicciones y valores deben mantenerse en una atmósfera de tolerancia real que se manifiesta en comportamientos que expresen la capacidad para entender y soportar tanto a otras personas que viven al tenor de convicciones diferentes a las nuestras como a sus conductas o comportamientos con estas personas y a reconocer que si bien hay diferencias, también hay muchas similitudes. De la misma manera, ayuda mucho en este proceso el valor de la serenidad que hace posible una actitud conciliadora y serena, de convivencia con otros en paz y tranquilidad a pesar del inevitable desasosiego de diferencia en ocasiones muy profundas. 


\section{LA ETERNA LUCHA DE LA CONCIENCIA HUMANA: LOS VALORES Y ANTIVALORES}

Uno de los problemas más serios para el cultivo de los valores en una sociedad que para la subsistencia de todos debe promover la tolerancia y la diversidad, es como confrontar el dilema entre valores y antivalores especialmente si estos últimos son atentatorios contra esta misma subsistencia. Este problema se hace especialmente crítico en los jóvenes que son bombardeados con toda clase de propagandas consumistas que atentan no solo contra su salud sino contra la supervivencia del planeta.

Estilos de vida "light" desenfrenados son una gran amenaza no solo para la generación presente sino para las venideras. Una reacción común ante el desenfreno de los medios masivos de comunicación que promueven conceptos distorsionados sobre la sexualidad, es el de tratar de inducir comportamientos a los niños/as y jóvenes con imposiciones dogmáticas como si con ellas se los pudiera proteger.

Los valores no pueden ser inducidos y mucho menos impuestos. Son elementos inminentemente construidos por la persona misma, se encuentran depositados en estructuras mentales muy profundas elaboradas por ella. Es importante que valores que promueven y defiendan la vida no nos conduzcan a posiciones dogmáticas impositivas y hasta persecutorias de seres humanos que sustenten valores o estilos de vida que no parecen concordar con la protección de la vida.

Si bien este estudio la examinará más en detalle al final, es necesario señalar brevemente que esta libertad supone un cultivo sistemático por parte de padres de familia y educadores de modo que nunca constituya una abierta licencia para actuar irreflexivamente ante la seducción avasalladora de antivalores impuestos por una propaganda, poderosa y eficaz que muy fácilmente abusa de la ingenuidad de tanta gente y rápidamente se impone al atractivo distante de valores morales cuya satisfacción no es ni inmediata ni sensible. El cultivo de la conciencia y de nuestra obligación de obedecerla es probablemente el desafío más grande que tienen la familia y los educadores a quienes ella confía tarea de tanta trascendencia para la realización de todo ser humano. 


\section{EL CONFLICTO DE VALORES Y ANTIVALORES EN TORNO A LA SEXUALIDAD}

Uno de los conflictos más graves entre valores y antivalores se da en torno a la sexualidad, conflicto que cada día crece con el impacto de una incontrolable y audaz propaganda que encuentra en ella un campo de acción inmensamente lucrativo.

La promoción de una visión de la sexualidad basada casi exclusivamente en las satisfacciones sensibles y físicas, impide que se aprecie al ser humano en toda su grandeza y plenitud, en las que su cuerpo con su maravillosa capacidad reproductiva y su dimensión psicoafectiva, con su posibilidad tan exclusivamente humana de romance, de vinculación de amor y ayuda mutua entre esposos, de formación de una familia y de aceptación responsable de las obligaciones de paternidad son la sinfonía maravillosa más grande de la creación.

La promoción de los antivalores insiste en que una persona "in" o de "buena onda", se debe considerar sexualmente liberada, sin ninguna clase de prejuicios o valores morales sexuales. Es lógico, entonces que si un medio de comunicación desea "cautivar" audiencias, simplemente tiene que, por una parte, mostrarse liberado de toda ética moral relacionada con la sexualidad y, por otra, usar sin escrúpulo alguno este don extraordinario del ser humano como excelente mercadería para un comercio riquísimamente productivo.

Dentro de esta visión mercantilista la sexualidad se convierte en mera genitalidad y la belleza de la persona humana es un simple cuerpo de mujer con ciertas características físicamente seductoras a fin de hacerla más atractiva y lucrativa en el comercio. El sexo se ha reducido así a un simple instinto animal, que puede ser satisfecho por una imaginativa variedad de artificios en los que no se atiende ni a los nocivos efectos físicos ni a los graves daños psicológicos, ni peor a las consecuencias de degradación ética o moral que puede causar.

Este mercantilismo promovido sistemáticamente para "vivir intensamente el momento" con gratificaciones tan animalmente instintivas, destruye los constitutivos más ’profundamente enaltecedores y genuinamente satisfactorios propios de la sexualidad humana.

Los medios masivos de comunicación que han destituido a la sexualidad de su verdadero sentido y las empresas que la promueven irresponsablemente presentándola por todas partes sólo como instrumento de placer, se niegan a aceptar que las grandes ganancias económicas de estos negocios tienen un costo incalculable, el irreparable daño de destruir uno de los tesoros más preciosos del ser humano. 
El reduccionismo de la sexualidad solo al placer está privando a grandes masas de población del disfrute de las satisfacciones más profundas que una persona puede tener en su exitencia, porque lo que da su sentido más importante a la sexualidad humana y lo que la enriquece distinguiéndola radicalmente de la animal, no es la respuesta al estímulo sensual de una seducción sino el poder alcanzar por medio de ella la realización del ser que busca mutua entrega amorosa de pareja, calidez y ternura de hogar, perpetuación en la fecundidad de familia y oportunidad única en la vida de cumplir el compromiso de hacer realidad un proyecto común acariciado con ilusión y entusiasmo (Michael, Gagnon y Lauman, 1994).

\section{EDUCACIÓN PARA LA SEXUALIDAD}

Es importante que los seres humanos aprendan desde su temprana edad a cultivar valores que les permitan comprender y apreciar la sexualidad en el sentido integral antes descrito, que va muchísimo más allá de gratificaciones sensoriales hacia una autoestima que ha de culminar en una realización personal extraordinaria en el contexto de fidelidad, lealtad y amor incondicional de pareja y de un hogar célula de una comunidad de colaboración y respeto.

Es importante ofrecer a los niños y a jóvenes, una educación muy cuidadosa que les facilite cultivar el valor de la sexogenitalidad a fin de que puedan disfrutarla con su propia finalidad tan rica y en un ambiente de seriedad, dignidad y corrección. Investigaciones muestran cómo la satisfacción rápidamente decae cuando se da en relaciones inestables, carentes de espontaneidad; y, sobretodo, de la entrega total e incondicional al otro/a.

Desde temprana edad deben los niños cultivar valores sólidos con respecto a la sexualidad, que les ayude a tomar una serie de opciones libres y responsables en el futuro. Obviamente este cultivo requiere de metodología adecuada, ajena a toda imposición y debidamente validada por sus efectos tanto de orientación con delicada atención para que el niño y adolescente crucen sus primeras etapas de curiosidad sexual y de búsqueda casi instintiva de satisfacciones, como de promoción sistemática de la salud, la vida, la dignidad de la persona, fundamentos sobre los que han de forjar una personalidad fuerte y segura de adultos maduros y responsables, capaces de manejar racionalmente su sexualidad, ser felices y contribuir a la felicidad de quienes les rodean.

Una educación que se limite a informar y explicar las dimensiones biológicas y fisiológicas de la sexualidad, fuera del contexto de los valores éticos y morales que atienden a su naturaleza específicamente humana, a su singular importancia derivada de la dignidad de la persona, del ecosistema familiar y comunitario, del compromiso de amor de pareja y de una paternidad 
responsable, puede causar consecuencias peligrosamente negativas, por ejemplo el que niños y adolescentes se sientan preparados y aun con derecho para empezar a experimentar la actividad sexual de adultos, actividad que, a su vez, puede tener graves y traumáticas secuelas como embarazos indeseados y prematuros, abortos, enfermedades venéreas, etc.

Esta educación debe insistir muy claramente en que para las relaciones genito - sexuales no basta el desarrollo físico, que puede darse a los 12 - 14 años, sino que es mucho más importante el desarrollo o madurez psico afectiva y social que generalmente sólo se logra después de los 20.

Una tarea importante de los padres, educadores y trabajadores en salud es ayudar a las jóvenes a entender su proceso de crecimiento y desarrollo y ser conscientes de sus procesos vitales, a fin que se preparen debidamente para asumir las diferentes opciones y riesgos que han de tener en sus vidas como también sus respectivas consecuencias a corto y largo plazo. Es muy conveniente que siendo la sexualidad un componente muy importante en la vida de todo ser humano, puede ser fuente de mucha felicidad, por ejemplo en las relaciones de pareja, si se la emplea apropiadamente, pero de mucho dolor y sufrimiento cuando se abusa de ella.

Las enfermedades venéreas de transmisión sexual como la gonorrea y el SIDA, los embarazos fuera de la familia con posibles abortos o juicios de paternidad y alimentos, el rompimiento de los hogares por la infidelidad con sus consiguientes traumas y complejos en padres e hijos, son los ejemplos más comunes del inadecuado manejo de la sexualidad.

\section{LA FAMILIA Y LA EDUCACIÓN SEXUAL DE JÓVENES ADOLESCENTES}

En general, el medio o contexto natural y más apropiado para una buena educación sexual es el ambiente familiar; y, muy probablemente el más adecuado para jóvenes adolescentes, porque el modelo de relación entre los esposos tiene gran impacto en sus actitudes y en su futuro.

Si deseamos vivir en armonía con la familia y con la sociedad, quizás sea muy oportuno, como un paso previo, organizar diálogos abiertos y honestos con padres de familia sobre la importancia y la manera de manejar responsablemente la educación sexual de sus hijos. Este diálogo, además de considerar aspectos anatómicos y fisiológicos, debe incluir aspectos ético - morales que consoliden "valores por la vida"; y, que constituirán un poderoso soporte de la vida comunitaria.

Estos diálogos que repetirán los padres con sus hijos, darán a los jóvenes espacios en los que puedan razonar y construir sus propios valores. Contribuirán así los padres directamente a la formación de seres humanos capaces de ejercer sus derechos de autodeterminación, guiados por valores que les harán menos vulnerables a las presiones propagandísticas de los medios de comunicación y que les posibilitarán crecer a plenitud como personas. 
Esta educación en familia tendrá también en cuenta el temprano despertar de las tensiones y deseos sexuales que experimentan los adolescentes y los jóvenes y su exacerbación por el permanente bombardeo de publicidad engañosa que fácilmente puede llevarlos a asumir una serie de conductas para lograr satisfacciones inmediatas.

Por sus propias experiencias de adolescencia y juventud tienen los padres una posibilidad muy real de orientar a sus hijos en el cultivo de una serie de valores que les ayuden a identificar conductas de riesgo para su salud psico- afectiva y biológica a fin de que, por una parte, no caigan en la satisfacción inmediatista de interactuar íntimamente con el sexo opuesto en formas inapropiadas; y, por otra, estén dispuestos a esperar a que se den las condiciones propicias en las que esta interacción se pueda realizar en plena libertad y entrega tota, de modo que los valores y la satisfacción de poder vivir de acuerdo a ellos y de encontrar formas correctas para expresarlos en conductas saludables, se conviertan para el joven y el adolescente en una inmensa satisfacción interna, y en una magnifica realización personal.

Nadie mejor que los padres puede ayudar a los jóvenes a comprender que disfrutar de la sexualidad sin compromiso ni responsabilidad ofende a la persona y le dificulta apreciar y mantener relaciones de genuina intimidad y entrega, que el verdadero amor siempre está dispuesto a esperar en contraste con el arrebato impaciente y egoísta de la pasión, que las gratificaciones por presión y coerción dejan un sabor amargo de frustración y atropello, que ser "mujer liberada" no significa que se entrega sexualmente a quien propone, que ser hombre o mujer realmente libre significa tener sus propios valores y convicciones; y, por tanto, el derecho a decir muy responsablemente "NO".

Los jóvenes deben conocer claramente que el sentido de pertenencia y de amor profundo que se experimenta a través de las relaciones sexogenitales en una vinculación estable de pareja, de ninguna manera puede ni alcanzarse ni perfeccionarse a través de experiencias ocasionales carentes de un compromiso de fidelidad y lealtad por el resto de la vida. Tienen que estar alertas ante el peligro de relaciones pasajeras que bajo el aparente intento de un acercamiento amistoso, tienden a convertirse en un poderoso foco de preocupación y atención que ahoga la amistad pero que no logrará sino un acercamiento de los cuerpos que ahoga la amistad, pero que no logrará sino un acercamiento de los cuerpos y acabará en un inevitable alejamiento como seres humanos.

Los padres de familia tienen que saber muy bien que la formación de hábitos indeseables es muy fácil cuando despiertan las curiosidades y las inclinaciones de carácter sexual. Conductas que permiten inmediatas satisfacciones de placer, rápidamente encuentra refuerzos muy poderosos para repetirlas. Las experiencias sexo - genitales pueden ser muy atractivas y emocionantes; y, en 
consecuencia, convertirse en hábitos aun antes de que el adolescente pueda ni siquiera visualizar ni peor comprender el daño que se hace a sí mismo y el que puede causar a los demás. El desarrollo de estos hábitos durante el período de crecimiento y formación del adolescente en el que se encuentra tan centrado en sí mismo -y en su propio placer del momento- constituye una dificultad muy grande para que en el futuro pueda el joven iniciar y cultivar relaciones maduras recíprocas para formar un hogar estable y feliz.

No es nada fácil el papel de los padres en contribuir con seriedad, prudencia, delicadeza y firmeza a que sus hijos, adolescentes y jóvenes, cultiven el valor de la abstinencia y autocontrol que les dará la capacidad de tomar decisiones legítimas y responsables precisamente para garantizar una segura y verdadera felicidad. Es muy duro para el adolescente y el joven dominar el volcán de emociones que tan rápidamente puede consumirles. Necesitan para ello la fortaleza de sus propios valores robustecidos en discusiones francas y críticas de familia y por el modelo convincente y el apoyo cordial, comprensivo y oportuno de sus padres. Sólo así podrán prepararse para escoger su pareja, para cuidarla con amor y respeto y asegurar una relación que cada día sea más significativa y placentera para ambos.

\section{LA SEXUALIDAD Y EL NOVIAZGO}

Cuando la persona demuestra que ha aprendido a dar y a darse desinteresadamente, está emitiendo una señal muy confiable de que va alcanzando su madurez; de que ya no se vive en función de tomar o poseer lo que le gusta, o de dar con el propósito de poder conseguir en retorno algo que desea, sino de entregar su amor sin condiciones y con entera libertad. De la misma manera, otra señal de madurez, si se aprende a recibir, no como algo que nos pertenece o que podemos exigir. Que gran maravilla, que invalorable tesoro el que dos seres humanos, maduramente, decidan en libertad entregarse mutuamente y sin reservas en todas las áreas, incluyendo la genito-sexual. Esto solo es posible cuando existe un claro compromiso de que esta entrega es recíproca e incondicional y de que los dos, por lo tanto, están dispuestos a luchar toda la vida para remover cualquier obstáculo que se interponga en la construcción de esa unión de pareja.

El conseguir una amistad y un/a compañero/a para todo un proyecto de vida es mucho más valioso que el lograr un placer sexogenital de momento. Madurez significa saber relacionarse con los demás, y muy especialmente, con la pareja de modo que efectivamente se contribuya al crecimiento y enriquecimiento mutuo. Esto demanda honestidad en la relación y un balance apropiado entre el nivel de intimidad que se tiene con cada persona y un nivel correspondiente de responsabilidad y compromiso. 
Poca intimidad implica poca o ninguna responsabilidad y viceversa. El conocimiento progresivo de otra persona y su identificación, primero con actividades e intereses; y, luego, con una determinada escala de valores, permite un desarrollo de una amistad más sólida y profunda, lo cual necesariamente conlleva una progresiva responsabilidad con la otra persona. Cuando los dos miembros de la pareja se sienten seguros de poder aceptar las consecuencias de esta responsabilidad mutua y libremente ante sí mismos y ante la sociedad, su voluntad de vivir permanentemente ese compromiso, están definitivamente listos para disfrutar esta entrega mutua plena y sin reservas.

Si la vida sexual es tan valiosa para el ser humano y fuente de tanto placer o de gran infelicidad, es indispensable que toda persona aprenda a manejarla responsablemente. Es natural querer tener relaciones sexuales, desearlas y soñar con las posibilidades de tenerlas ya que ellas por naturaleza son algo hermoso para la persona, no solo porque permiten el milagro de la reproducción de la especie, sino porque son una expresión de intimidad profunda y de total pertenencia entre dos seres. Sin embargo, aún estos justos deseos y sueños deben manejarse con mucha responsabilidad y cuidado sumo, ya que pueden abrir caminos a situaciones altamente destructivas para la personalidad.

Esta responsabilidad implica el desarrollo de la capacidad de muchas veces decir "No" a deseos u oportunidades que se presenten pero que traen serias consecuencias para su vida, su familia y/o un posible nuevo ser. Aún más importante es tener la firmeza para no exponerse a situaciones donde va a ser muy difícil decir un necesario "No".

Estos obvios temores y estas serias inquietudes exigen un singular esfuerzo por desarrollar y robustecer una unión muy poderosa con un vínculo fuerte que permita a la pareja sobreponerse a muchas dificultades y tensiones que irán apareciendo en su relación a través del tiempo. En este contexto la sexualidad se convertirá en una fuente permanente de gozo y placer para ambos en donde las relaciones sexuales podrán saborearse y explorarse de muchas formas sin temores, dudas, complejos de culpa o incertidumbres.

Todas estas consideraciones deben ser objeto de cuestionamientos y razonamientos abiertos y francos por parte de la pareja, porque, además de permitirles desarrollar un marco teórico más integral de lo que es la sexualidad, les ayudarán a consolidar los valores que la enaltecen y a desarrollar los comportamientos más adecuados para vivirlos. Es importante que adquieran habilidades que les permita salir rápidamente de situaciones de riesgo. Es muy sabido que tanto las mujeres como los hombres pueden presionar y acosar a su pareja a tener relaciones genito-sexuales. Ellas y ellos deben conocer que el noviazgo puede ser ocasión para estas conductas y que justificarlas, como: "Si no lo haces eres una niña inmadura", "No te preocupes que después me 
casaré contigo", "Te vas a sentir lo más bien y nunca lo olvidaremos", "Si lo hacemos de cierta forma, estaremos seguros que no quedarás embarazada", "Toda mujer moderna y liberada hace el amor", etc.

\section{CONCLUSIONES}

La libertad de conciencia y la capacidad de impedir que otros controlen nuestra mente son los dones más preciados del ser humano y los mejores medios para sobreponernos a la masificación y a las malas influencias. Nuestras mentes no fueron hechas para ser receptores inertes y mudos de quienes depositan en ellas toda clase de publicidad engañosa para manejar nuestras conductas y convertirnos así en dóciles ovejas del montón. Nuestra conciencia tiene que rebelarse ante semejante intrusión y obligar a nuestra mente a dedicarse a la dinámica reactivación de ideas, reflexiones y sólidos criterios que propicien el cultivo de valores de respeto a la vida y a la persona.

Los valores juegan un papel crucial en el mantenimiento de la libertad de conciencia con dignidad y respeto para consigo mismo y para con los demás, para que a través de conductas responsables podamos construir un mundo más humano y justo para todos.

Las conductas sexuales son un excelente ejemplo para comprender mejor el papel que tienen los valores en la determinación de los comportamientos. Si una persona puede asumir responsabilidad por su conducta y estar dispuesta a manejar de manera responsable sus deseos y pasiones sexuales, fácilmente podremos comprender cómo una persona puede estar dispuesta también a anteponer sus intereses personales egoístas, valores como el amor, el servicio, la lealtad, la solidaridad, la reciprocidad, la justicia, etc.

Si los seres humanos en lugar de aceptar pasivamente los efectos de la "aculturación que se impone n múltiples formas", tienen la posibilidad de construir sus propios valores; y, al mismo tiempo, de construir modelos en los que pueden visualizar cómo estos valores les permiten vivir intensamente, habrán equipado su personalidad con los mejores motivadores capaces de proveerles permanente recompensa intrínseca por sus comportamientos. Obviamente, no se puede menospreciar el papel que el soporte social tiene en la reafirmación de esos valores. Cuando lleguen las consecuencias incidentales de vivirlos, éste reforzará las decisiones de haber optado por vivir de acuerdo a ellos.

Cuando los valores están fuertemente arraigados en la persona, se convierten en poderosos elementos de "autoeficacia" o del grado en el que la persona tiene confianza en su capacidad para lograr objetivos en su vida. Le dan fortaleza para perseverar en estilos de vida acordes con sus convicciones, a pesar que el entorno pueda ser hostil o no motivador. Como se muestra en varios estudios presentados por Brunig, Schraw y Ronning (1995, pp132) “...la autoeficacia está muy ligada 
con el involucrarse, el persistir y el poder tener un desempeño exitoso". Así es como los valores se constituyen en elementos fundamentales para poder lograr la convivencia pacífica en el ecosistema familiar, instituciones y social.

\section{BIBLIOGRAFÍA}

Bruning, R.H., Schraw, G.J., y Ronning, R.R., Instrucción y Psicología Cognitiva, Estados Unidos, Englewood Cliffs, N.J: Prentice Hall, 1995.

Cohen, S.J., Halvorson, H.W., y Gosselink, C., Changing physician behavior to improve disease prevention. Preventive Medicine, Prentice Hall, New Jersey, 1994.

De Angulo, José Miguel y Losada, Luz Stella, La Epistemología y sus desafíos para el día de hoy: Aprendizaje basado en problemas, aprendizaje basado en la comunidad, Cochabamba, MAP Internacional, 1998.

De Angulo, José Miguel y Losada, Luz Stella, La Autoestima y la Dignidad: Requisitos para construir una vida abundante, 2da. Edición, Bolivia, Visión Mundial Internacional, Offset Druck y Co., 1992.

De Angulo, José Miguel y Losada, Luz Stella, ¿Qué es y cómo cuidar el ecosistema de la familia?, Cochabamba, MAP Internacional, 1992.

Gagnon, Michael y Lauman, J.I., Problem-Based Learning as an Educational Estrategy, New York, Network Publications, 1994.

Gletman, H., Psychology, 4th ed., New York: W.W. Norton,1995

Prochaska, J.O., y Di Clemente, C.C., Toward a comprehensive model of change. En: W.R., y Heather, N (editores), Treating Addictive Behaviors: Processes of Change, New York: Plenum Press,1986. 